Provided for non-commercial research and education use. Not for reproduction, distribution or commercial use.

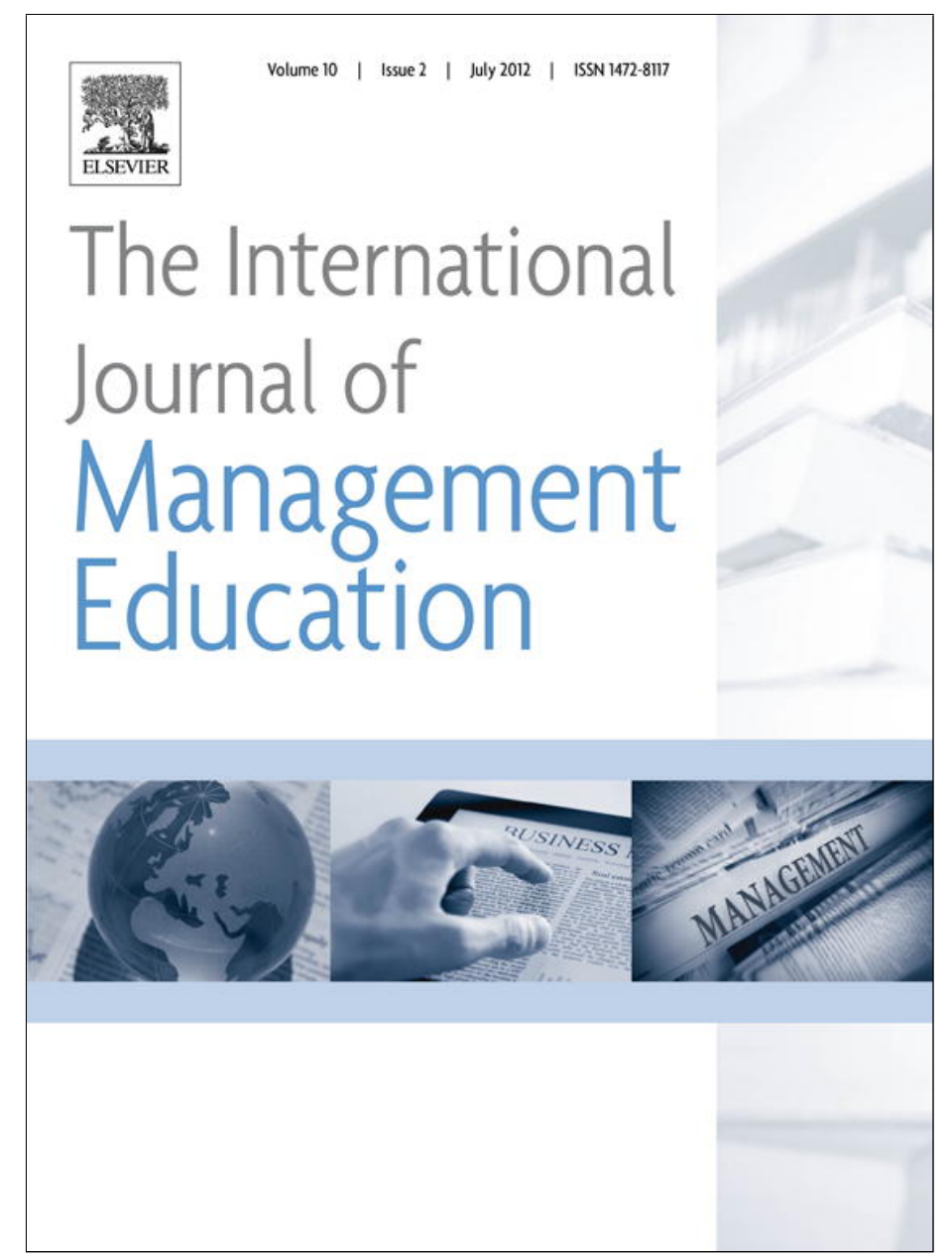

This article appeared in a journal published by Elsevier. The attached copy is furnished to the author for internal non-commercial research and education use, including for instruction at the authors institution and sharing with colleagues.

Other uses, including reproduction and distribution, or selling or licensing copies, or posting to personal, institutional or third party websites are prohibited.

In most cases authors are permitted to post their version of the article (e.g. in Word or Tex form) to their personal website or institutional repository. Authors requiring further information regarding Elsevier's archiving and manuscript policies are encouraged to visit:

http://www.elsevier.com/copyright 


\title{
Evaluation of a global blended learning MBA programme
}

\author{
Yongmei Bentley*, Habte Selassie, Elizabeth Parkin
}

The University of Bedfordshire, Park Square, Luton, Bedfordshire LU1 3JU, UK

\section{A R T I C L E I N F O}

\section{Article history:}

Received 25 February 2011

Received in revised form 29 February 2012

Accepted 19 March 2012

\section{Keywords:}

Blended learning

Student experience

Course evaluation

Action research

\begin{abstract}
A B S T R A C T
This paper evaluates the design and implementation of a UK university's global blended learning MBA programme which combines e-learning with face-to-face teaching. The primary aim of the research was to investigate the learning experience and perceptions of the students, and to use the findings to evaluate the effectiveness of the course design and delivery system. Action research was used, with longitudinal data collected over a threeyear period (2008-2010). Three survey rounds were conducted focussing on Oman, one of the UK University's main overseas learning collaborating centres. The three rounds yielded 116 valid responses in total. The first survey showed a fairly high level of student satisfaction with the programme but also indicated areas that needed further improvement. The impacts of subsequent changes in the programme were investigated in the second and third surveys. Feedback from these helped develop further changes in the learning content and delivery approach of the programme. The study contributes to a better understanding of global blended learning initiatives, and offers insights to managers on improving course management, enriching learning content, enhancing teaching quality, and improving students' satisfaction levels.
\end{abstract}

(c) 2012 Elsevier Ltd. All rights reserved.

\section{Introduction}

Blended learning is a form of learning that combines the features of e-learning with those of classroom teaching. According to Singh (2003) blended learning provides various benefits over using any single delivery medium alone. However, the creation and implementation of effective quality assurance for blended learning processes has been identified as one of the more challenging tasks. Jara and Mellar (2010) and Martínez-Argüelles, Castán, and Juan (2010) point out that the collection of student feedback should be a central part of strategies to monitor the quality and standards of teaching and learning for both conventional learning and e-learning. Jara and Mellar (2010) also note that while research into e-learning abounds, studies that focus on the effectiveness of the provision of such learning (including blended learning) are limited, and that this is a gap to be filled.

E-learning and blended learning continue to develop rapidly, supported by increasing sophistication of information technology and by better understanding of how to make course content and delivery more effective. In addition, new forms of e-learning support systems are being introduced to higher education institutions in an effort to meet the student-centred learning paradigms recommended by UNESCO (UNESCO, 1998).

The research reported here discusses the evaluation of a global Executive MBA blended learning programme provided by a UK University, and focuses on one of its main overseas partnering centres - that of Oman. The research aimed to investigate the learning experience and perceptions of the students on the course, and use the findings to evaluate the effectiveness of

\footnotetext{
* Corresponding author. Tel.: +44 (0) 1234400400.

E-mail address: yongmei.bentley@beds.ac.uk (Y. Bentley).
} 
the blended learning support system in place. The research was aligned with the four quality dimensions identified by Martínez-Argüelles et al. (2010) - the learning process, administrative processes, teaching materials, and resources.

The primary research method was action research, within which the main data collection was by questionnaire surveys of students taking the course over a three-year period. Three survey rounds were conducted, resulting in a total of 116 valid responses.

This paper begins with a review of relevant literature, including e-learning and blended learning, quality evaluation and enhancement, and the blended learning situation in Oman. An overview of the MBA blended learning programme is then provided, followed by a discussion of the research methodology adopted. Findings from each of the three survey rounds are then presented, and discussion of these is set in the context of improvements made to the course. Finally, research limitations are listed, and conclusions are drawn.

\section{Literature review}

\subsection{E-learning and blended learning}

The rapid growth of online academic course provision worldwide has changed the learning environment for both students and teachers (Landry, Payne, \& Koger, 2008; Lapointe \& Reisetter, 2008; Williams \& Williams, 2010). E-learning takes many forms, such as fully online, mixed mode or hybrid, blended learning and web-assisted (Buzzetto-More, 2008). It is claimed that e-learning overcomes many drawbacks that are inherent to traditional classroom teaching, especially its lack of flexibility in the use of resources (for example, Lam \& Bordia, 2008; Williams \& Williams, 2010). Goold, Craig, and Coldwell (2007) indicate that the online learning environment enables a greater number of students of diverse educational and cultural backgrounds, as well as of modes of study, to come together within the one virtual classroom. However, they warn that many of the clues that help enable staff and students to be culturally sensitive in physical classrooms are missing in the online world. For this and other reasons, it has been suggested that students need better preparation for learning in an online environment than in a traditional classroom.

One particular implementation of e-learning is blended learning. According to Singh (2003: 52) 'blended learning combines multiple delivery media that are designed to complement each other and promote learning and application-learnt behaviour'. Typically, blended learning includes face-to-face classroom teaching, live e-learning, self-paced e-learning, and structured off-line study including set readings and assignments.

\subsection{Quality evaluation, assurance and enhancement}

The research described here is based on analysing student feedback on a wide range of aspects of course provision. The findings thus relate to issues of course quality evaluation and assurance, as well as to course enhancement.

Saunders (2003: 39) defines evaluation as the 'purposeful gathering, analysis and discussion of evidence from relevant sources about the quality, effectiveness, and impact of provision, development or policy'. Because of the remote nature of elearning, quality evaluation, assurance and enhancement is a particular issue.

Rajasingham (2009) and Guri-Rosenblit (2009) note that e-learning evolved from distance education and is still struggling to gain full recognition and accreditation within mainstream education as an approach for high quality provision. Moreover, as Pillay and Kimber (2009) point out, globalisation, trans-national provision of higher education, and the 'use of market mechanisms' have all increased the complexity of issues concerning accountability, authority, and responsibility within quality assurance.

In terms of quality assurance, Zygouris-Coe, Swan, and Ireland (2009) note that instituting a well-structured assurance process can be expensive and time consuming, but that it can be worth the effort. The study undertaken by Kidney, Cummings, and Boehm (2007) supports this. The latter state that the merit, quality and success of the e-learning programme they investigated was mainly due to the proper application of the quality assurance strategies. Moreover, Rajasingham (2009) notes that new educational paradigms and models that challenge conventional assumptions and indicators of quality assurance are becoming possible with the help of increasing sophistication in information technology.

Deepwell (2007) draws a distinction between quality assurance and quality enhancement, and views student evaluation as an instrument of quality enhancement rather than quality assurance. In a narrow sense this is correct, as quality assurance as this relates to course content, adequacy of delivery, and quality of exams and marking, must be covered by procedures implemented by the originating and partnering institutions to ensure that agreed standards are met.

Though student evaluation often gives information about the above issues, here we accept the concept that student feedback primarily affects the wider quality issues identified by Moore (2006), who lists the five 'pillars of quality' for on-line programmes as learning effectiveness, cost-effectiveness and institutional commitment, access, faculty (employee) satisfaction, and student (customer) satisfaction. In this sense, student evaluation has less to do with quality assurance, and more to do with quality enhancement.

However, even within this definition there are mixed reports as to effectiveness. For example, Gurău and Drillon (2009) state that analysing users' perceptions regarding an e-learning system can provide valuable data to evaluate and improve its functioning and performance. On the one hand, Jara and Mellar (2010) report from their research findings that student 
feedback was not always fully adequate to support quality enhancement. In the case of the research reported below, however, it is clear that the student feedback was indeed useful for course quality enhancement.

Finally, Martínez-Argüelles et al. (2010) identified four 'quality dimensions' that they saw as key for course provision, and these are incorporated in the questionnaire design described later. These dimensions are: the learning process, administrative processes, teaching materials, and resources.

\subsection{E-learning and blended learning in Oman}

With the above background, it is useful to briefly review the status of e-learning and blended learning in Oman. Because elearning can supplement face-to-face learning and also make distance learning possible (Musawi, 2002), its flexibility is believed suitable for the education system of a country such as Oman, where the population is sparsely distributed over a relatively large area. Students can log onto an e-learning system from their educational institutions, cyber cafés, their homes, as well as via mobile phones and similar apparatus. It is not surprising therefore that the Ministry of Higher Education of Oman has introduced an e-learning system throughout the country's universities and colleges.

As a result, it is now widely believed that e-learning provides students and staff a good platform for up-to-date and effective teaching and learning (Singh, 2011). A number of studies on e-learning in Oman have been carried out. For example, Al-Gattoufi, Al-Naabi, and Gattoufi (2007) examined the shift from traditional learning to an e-learning system in a case study of Oman's Nizwa College, and they identified strengths, weaknesses and problem areas with implications to other learning institutions across the country. In another study Elango, Gudep, and Selvam (2008) examined the perception of students regarding the quality of e-learning delivery in both Oman and the UAE and found very encouraging trends, but also identified areas for improvement.

On the basis of the above, the UK University's blended learning MBA programme described here fits well into the new educational policy of Oman, and benefits from strong support from government.

\subsection{The need for research into e-learning and blended learning}

Lapointe and Reisetter (2008) suggest that the new reality of online learning demands a reassessment of our understanding of what makes for the most productive student engagement. More particularly, Singh (2003) points out that there is little formal research on how to construct the most effective blended programme designs. The findings below are intended to help move towards answers to these questions.

\section{Overview of the MBA programme}

The MBA programme discussed in this article has been delivered to work-based part-time students in the UK for about ten years, and more recently at overseas centres in Oman, Switzerland, Germany, Poland, India, and South Africa. When delivered overseas, this is a close collaboration between the UK University and a specific higher education institution in the partner country.

The course is delivered primarily online via the UK University's e-learning support system, but also by periods of face-toface classes which can be taken at the overseas partner institution, the UK University, or at both. In the case of the overseas centres, the face-to-face teaching is delivered by the faculty of the UK University and also by staff from the partner institution. The UK lecturers prepare and upload all the online course content, including required and optional reading, explanations of key learning points, and guidelines to studying. They also set and mark all the assignments and examination scripts.

In 2010 when the latest survey reported here was carried out, there were nearly 240 students in total taking the course across all sites, of which 133 (i.e. 55\%) were based in Oman. Students on the course are required to take and pass ten course units to complete the programme - eight taught units ( 15 credits each) and two applied management projects (30 credits each). It normally takes two years for work-based students to complete the course. The revised course structure of this programme, based in part on the findings from the first two surveys, consists of five units in the first year and five in the second, as shown in Fig. 1.

Fig. 2 shows the main building blocks of the MBA blended learning system, which demonstrates the range of learning modes that are available to the students.

At the start of each semester the UK university staff conduct induction sessions for the students at the overseas centres, and this is followed by two days of face-to-face teaching. The main purpose of this approach is to give the students an overview of each unit, get them started with their learning and set out what is expected of them in terms of assessments through the semester.

The e-learning system used is Blackboard (branded here as BREO) with tutors using this to provide materials to students. Other BREO facilities for student interaction include discussion boards, and blogs. Use of these interactive tools by UK staff varies, as some have developed more skills in using online interaction than others.

The support systems available through BREO include WIMBA (a voice over Internet system) and the Turnitin system. WIMBA is a plug-in WebCT Vista which has 'live classroom' and 'voice tools' components by which the tutor and the students in different locations can hold a virtual class simultaneously, see each other via the webcam, and talk to each other as in a traditional classroom. WIMBA provides a forum, among other things, for UK lecturers to gain a good grasp of the progress 


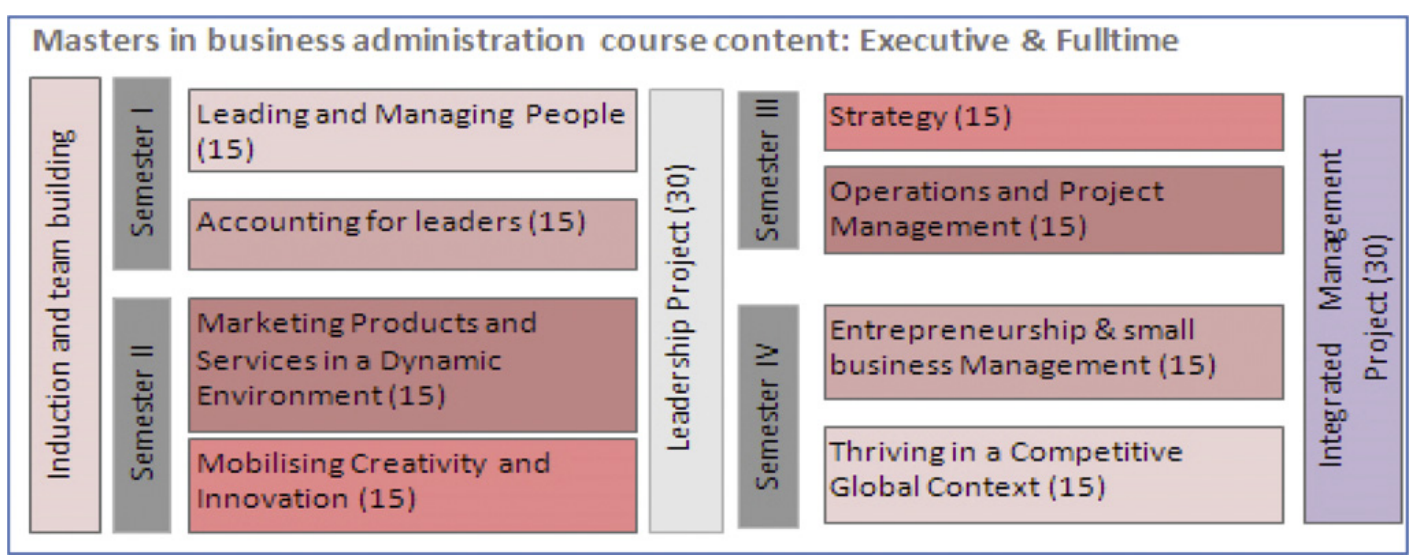

Fig. 1. MBA course structure (Priestman, 2010).

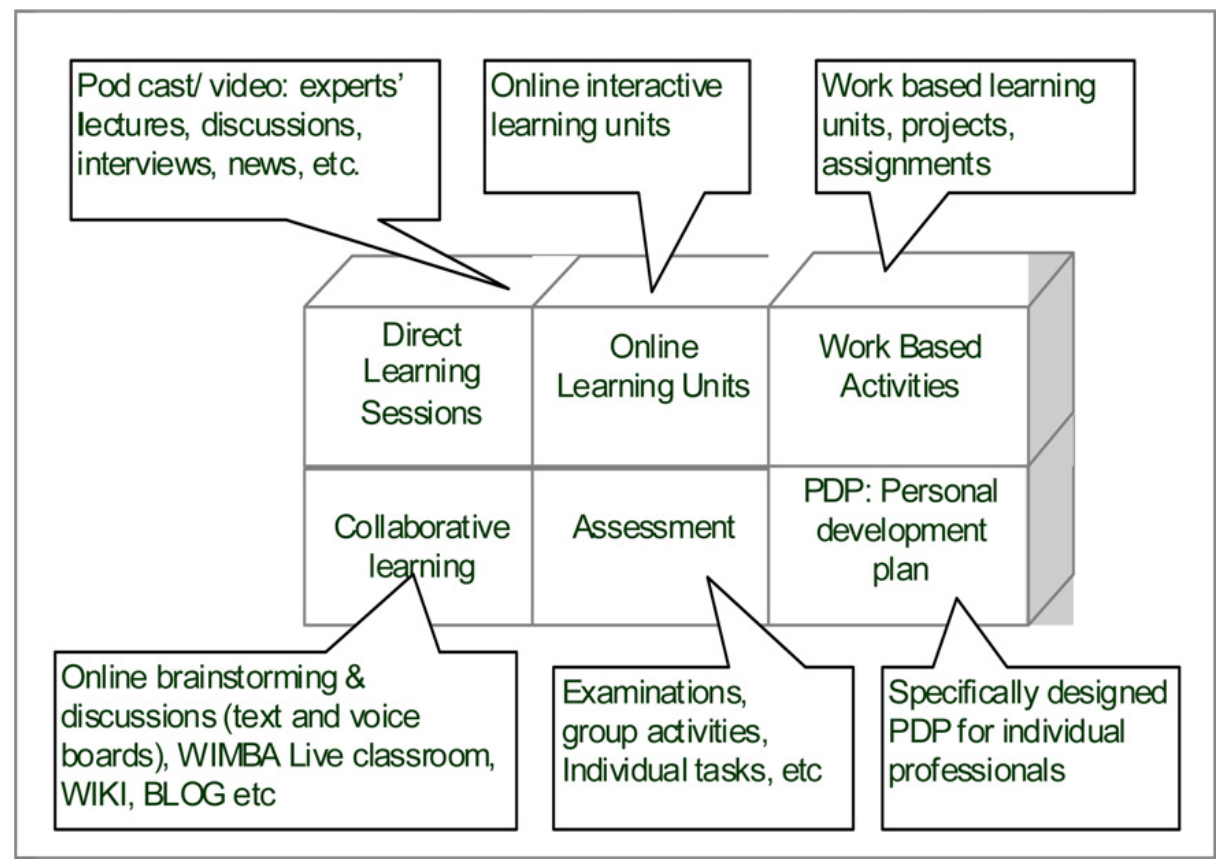

Fig. 2. The blended learning structure of the Executive MBA programme (Priestman, 2010).

that the students have made, answer their questions related to the subject, and provide additional support for their coursework and examinations. The Turnitin system is an online plagiarism checker for course assignments, and is one means to check the extent to which assignments submitted for the course are written by the students themselves. In addition, all MBA students have full online access to the university's digital library. Overall, the programme reflects the dimensions of elearning that incorporates ‘self-paced and live, collaborative learning' (Singh, 2003).

\section{Research methodology}

The research methodology used for this study was action research (AR). A number of definitions exist for AR, and it is generally taken as referring to a class of research approaches, rather than a single method (Baskerville, 1999). However the various forms share agreed characteristics as follows: having both an 'action' and a 'change' orientation; include participation with the people involved in the research process; be a process seen as educative and empowering; and one which involves stages (sometimes iterative) of problem identification, planning, action and evaluation. This research fits the above criteria. It was conducted by the authors, who are also members of the MBA team responsible for the development and delivery of the programme; there was direct two-way interaction with the students involved in the research; and it involved a series of iterative actions to change the situation under study. 
Table 1

Mapping the 'quality dimensions' with the questionnaire components.

\begin{tabular}{ll}
\hline Quality dimensions by Martinez-Argüelles et al. (2010) & Corresponding components in the questionnaire \\
\hline Administrative process & Course and unit administration \\
Resources (staff, facilities) & E-learning support systems \\
Teaching materials & Teaching materials \\
The learning process & Course and unit information \\
& Teaching and tutor support \\
& Assignment support and feedback \\
& Students' overall experience of taking this course \\
\hline
\end{tabular}

Within this AR, a sequence of semi-structured questionnaire surveys was used as the primary research method to collect data from respondents over time. The questionnaire design was based on the model of 'quality dimensions from the students' perspective' proposed by Martínez-Argüelles et al. (2010) as discussed earlier: administrative processes, the learning process, teaching materials, and resources. The main elements of the questionnaire covered course administration, teaching and tutor support, teaching materials, e-learning support systems, assignment support and feedback, and students' overall experience of taking the course. These elements were seen as key for measuring the quality of the programme provided to the students. Table 1 illustrates each of the quality dimensions and the corresponding components designed for the questionnaire.

In order to examine the changes that occurred in the attitudes and satisfaction levels of the students, three rounds of survey were conducted during the 3-year period from 2008 to 2010 . As the focus of the evaluation was on improving the quality and effectiveness of the course provision, the outcome of changes themselves needed evaluation. For this reason, surveys after the first contained some questions that were different from those in the survey prior.

\section{Research findings and discussion}

\subsection{Overview of the surveys}

Table 2 gives an overview of all three surveys conducted over the period. The questionnaires were distributed both online and off-line. In total, 116 valid responses were returned from 257 students receiving the questionnaire, representing a $45 \%$ response rate. The questionnaire was voluntary, and this relatively high rate reflects in part the effectiveness of the method used for questionnaire distribution and return.

Table 2

Summary of survey respondents of all three surveys.

\begin{tabular}{lccc}
\hline Surveys & No. of responses received & No. of responses expected & Response rate \\
\hline 1st survey (2008) & 30 & 41 & $73 \%$ \\
2nd survey (2009) & 37 & 83 & $45 \%$ \\
3rd survey (2010) & 49 & 133 & $37 \%$ \\
Total responses & 116 & 257 & $42 \%$ \\
\hline
\end{tabular}

\subsection{Respondents' profile}

The first part of the questionnaire covered the respondents' personal details including gender, age, nationality, and current employment title. This information was relevant in determining whether the course design would fit the learners' cultural background, learning behaviour, and so on. The results showed that most of the respondents were male students, with less than one quarter being female. Over 80\% of them were from Oman itself, with about one-fifth from neighbouring countries including UAE and Southwest India. The average age was 35. Most respondents held middle or senior management positions; for example, job titles of participants in the first survey included: Assistant Manager, Contracts Team Leader, IT Support Manager, Deputy Director, Director of Air Traffic control, Operations Manager, KPI and Project Manager, General Manager, Senior Accountant, and Senior Document Controller.

\subsection{Outcome of the first survey}

The first survey had 30 questions and every question was given a response choice of 'excellent', 'good', 'average' and 'poor'. The results for this first survey are given in Table 3. The overall results showed a fairly high level of satisfaction with the programme, with an average of $66 \%$ of the respondents perceiving the average of the 30 aspects of the course as either 'excellent' (22\%) or 'good' (44\%), versus $25 \%$ perceiving this as 'average', and $9 \%$ as 'poor'. 
Table 3

Results from the 1 st survey (\% response by category).

\begin{tabular}{|c|c|c|c|c|c|c|c|}
\hline Q & Survey items & $\%$ of excellent & $\%$ of good & $\%$ of average & $\%$ of poor & Total \% of E\&G & Total \% of A\&P \\
\hline 1 & Registration process & 27 & 60 & 10 & 3 & 87 & 13 \\
\hline 2 & Teaching at induction by UK university & 20 & 63 & 14 & 3 & 83 & 17 \\
\hline 3 & Teaching at local institution & 23 & 60 & 17 & 0 & 83 & 17 \\
\hline 4 & Course/unit handouts & 30 & 50 & 17 & 3 & 80 & 20 \\
\hline 5 & Local tutor support & 20 & 40 & 40 & 0 & 60 & 40 \\
\hline 6 & Course/unit information from local institution & 17 & 63 & 20 & 0 & 80 & 20 \\
\hline 7 & Learning support at induction & 37 & 20 & 33 & 10 & 57 & 43 \\
\hline 8 & Local support facilites & 13 & 40 & 37 & 10 & 53 & 47 \\
\hline 9 & Textbook availability & 27 & 46 & 17 & 10 & 73 & 27 \\
\hline 10 & Learning materials on CD ROMS & 23 & 37 & 27 & 13 & 60 & 40 \\
\hline 11 & Reading materials on BREO & 45 & 34 & 21 & 0 & 79 & 21 \\
\hline 12 & Learning resources & 23 & 47 & 23 & 7 & 70 & 30 \\
\hline 13 & UK tutor support & 20 & 47 & 30 & 3 & 67 & 33 \\
\hline 14 & Slides on BREO & 36 & 47 & 17 & 0 & 83 & 17 \\
\hline 15 & Use of audio/video clips & 5 & 40 & 30 & 25 & 45 & 55 \\
\hline 16 & Relevant website links & 23 & 37 & 33 & 7 & 60 & 40 \\
\hline 17 & Voice Café & 20 & 13 & 17 & 50 & 33 & 67 \\
\hline 18 & Course/unit response & 3 & 53 & 37 & 7 & 56 & 44 \\
\hline 19 & E-learning training and support & 17 & 27 & 43 & 13 & 44 & 56 \\
\hline 20 & Assignment instructions & 13 & 63 & 17 & 7 & 76 & 24 \\
\hline 21 & Assignment submission procedures & 20 & 53 & 14 & 13 & 73 & 27 \\
\hline 22 & Assignment feedback & 10 & 40 & 37 & 13 & 50 & 50 \\
\hline 23 & Referral procedure & 19 & 37 & 38 & 6 & 56 & 44 \\
\hline 24 & Failure procedures & 27 & 27 & 18 & 28 & 54 & 46 \\
\hline 25 & Academic offence procedures & 28 & 29 & 22 & 21 & 57 & 43 \\
\hline 26 & Social networking opportunities & 7 & 50 & 27 & 16 & 57 & 43 \\
\hline 27 & Overall quality of e-learning materials & 23 & 63 & 10 & 3 & 86 & 13 \\
\hline 28 & Overall experience with the tutors & 27 & 56 & 17 & 0 & 83 & 17 \\
\hline 29 & Overall experience of online support & 13 & 47 & 30 & 10 & 60 & 40 \\
\hline \multirow[t]{2}{*}{30} & Overall experience of undertaking the MBA & 27 & 40 & 30 & 3 & 67 & 33 \\
\hline & Average Percentage: & 21 & 44 & 26 & 9 & 66 & 34 \\
\hline
\end{tabular}

In terms of overall quality, 26 out of the 30 aspects surveyed showed a combined percentage of 'excellent' and 'good' to be greater than the combined percentage of 'average' and 'poor'. There were 8 aspects where the combined 'excellent' and 'good' percentages were over $80 \%$. The respondents were particularly happy with the following: registration process, teaching by UK and local tutors, course and unit information, e-learning materials and the overall experience with the tutors. However, some results were not satisfactory. In particular, one area (assignment feedback) had a 50:50 percentage split, while three had the percentages significantly reversed. These latter were question 15 - use of audio/video clips (45\% vs. 55\%), question 17: Voice Café (33\% vs. 67\%), and question 19: e-learning training and support (44\% vs. 56\%). So there existed room for improvement.

As this was a semi-structured questionnaire survey, the respondents were given the opportunity to offer comments where appropriate in order to provide more detailed information on the areas being investigated, and to encourage suggestions for improving the course.

Examples of positive comments included:

- 'Voice over the Internet, Blackboard, and the student records system are excellent facilities for remote students like us. I found this course very balanced and suitable for working candidates'.

- 'I was impressed with the free wireless Internet facility and the ever-helpful nature of the faculty office and administration team'.

- 'It has been really a correct decision for me to enrol onto the MBA programme. The wisdom I derived from [taking this] eMBA is tremendous'.

- 'It was a pleasure and enjoyable experience taking the MBA with this UK University'.

Not surprisingly, there was also a range of negative comments, and the ratio of positive to negative comments was about 50:50. To put these into context it needs to be borne in mind that the students were mostly at middle and senior-level management in full-time employment, and were working on the Executive MBA often on day or week release schemes from their employer, and at weekends. As a result, student expectations of the course were generally high, and the time pressure on the students often quite onerous.

The following are examples of some of the areas of criticism:

- Many respondents asked for more consistent and comprehensive module information and guidance, clearer assignment instructions, and for the formats of examinations. Some mentioned that they had a desire to have all the essential information about the course issued at the induction sessions (rather than having some information fed piecemeal later). 
- A few respondents expressed a dislike for the different assignment submission systems used on different courses within the MBA, as these were often seen as time-consuming and confusing.

- Some felt very dissatisfied if they failed to receive their assignment feedback within the specified time, but appreciated the cases where more detailed and customised feedback had been given, rather than just a brief and general comment, as they wanted to understand what was wrong in their work. They also had a desire for quicker responses to requests for information and feedback.

- Some felt that BREO had been under-used, e.g. it was not used to provide effective discussion forums.

- Some felt the need to spend more time with the UK-based tutors, and expressed a wish for an additional round of face-toface interaction in the middle of a semester from the UK course leaders. Some would have liked to gain the opportunity for the classroom experience at the UK University.

- In addition, it was suggested that the communication and collaboration between the education partners be improved, so that better and more effective on-line support could be provided.

Overall, the above comments indicated a need for more support to the students' learning process. Though Table 3 showed that there were quite a lot of positive responses ('excellent' plus 'good') on the support for e-learning itself, the perceptions of the respondents also showed that there was still room in a number of areas for improvement.

Findings from the first survey, together with additional feedback collected from consultation with both the UK and local staff, were considered in detail. Subsequently, a significant range of changes to the programme were made. Table 4 summarises the key issues identified, the changes suggested, and the actions taken after the first questionnaire survey.

\subsection{Outcome of the second survey}

The second survey was conducted in 2009 and 37 valid responses were received of which 30 were completed in class, and 7 online. This survey had 18 questions the same as in the first survey, but it also had additional questions to evaluate areas introduced after the first survey. The primary purpose of this survey was to measure any improvement (or otherwise) resulting from the course changes, and to uncover additional issues. A comparison of the results between the two survey rounds is given in Table 5. (For consistency, the item numbers are the same as those used for the first round as shown in Table 3.)

An examination of the results from the first two surveys showed that 12 out of the 18 topic areas investigated in common across the surveys had improvements in the second survey in the 'positive' response category (\% of 'excellent' plus 'good'), with four areas showing a gain of 10\% or more. Such improvements included: teaching at induction by the UK university (from $80 \%$ to $90 \%$ ); e-learning training and support (44\%-67\%); assignment feedback (50\%-67\%); and overall experience of online support (67\%-77\%). Other assignment related areas measured had also slightly improved: assignment instructions (76\%80\%); assignment submission procedures (73-80\%); and referral procedure (55\%-63\%). For question 10, changed from providing 'learning materials on CD Rom' in the first survey to providing 'weekly online material' in the second, the percentages in the 'Excellent' plus 'Good' categories had risen from 60\% to 77\%. Likewise, for question 17 (changed from using 'Voice Café' for Internet conference in the first survey to the adoption of 'WIMBA' in the second), the percentage rise was 33\%$60 \%$.

Table 4

Key issues identified from the first survey, suggestions and actions.

\begin{tabular}{|c|c|c|}
\hline Key issues & Changes suggested & Actions taken \\
\hline $\begin{array}{l}\text { 1. Problems with Voice Café (unclear } \\
\text { voice, vague images, limited functions, } \\
\text { and poor design of user interface) }\end{array}$ & $\begin{array}{l}\text { To replace Voice Café with a more advanced } \\
\text { and user friendly tool }\end{array}$ & $\begin{array}{l}\text { WIMBA Live Classroom } \\
\text { implemented to overcome } \\
\text { the problems of Voice Café. }\end{array}$ \\
\hline 2. BREO had been under-used & $\begin{array}{l}\text { To improve the usability of BREO by making } \\
\text { more learning material available online, and } \\
\text { use the BREO assignments tool to submit } \\
\text { assignment online. }\end{array}$ & $\begin{array}{l}\text { The tutors were required to } \\
\text { provide additional online learning } \\
\text { contents for each week (e.g. research } \\
\text { papers, cases, video/pod cast clips) } \\
\text { in addition to the basic learning } \\
\text { materials, and students were } \\
\text { required to submit assignments and } \\
\text { receive feedback online. }\end{array}$ \\
\hline $\begin{array}{l}\text { 3. Students required having more } \\
\text { time with UK tutors, especially in } \\
\text { terms of getting extra support } \\
\text { about assignments. }\end{array}$ & $\begin{array}{l}\text { To deliver more WIMBA sessions and give } \\
\text { clearer assignment guidance to students } \\
\text { well before the deadline for each assignment } \\
\text { submission. }\end{array}$ & $\begin{array}{l}\text { Tutors were scheduled to give more } \\
\text { frequent online sessions via WIMBA } \\
\text { Live Classroom to enable synchronous } \\
\text { communication; and to archive materials } \\
\text { generated from the WIMBA sessions so } \\
\text { that they can be re-used and re-visited } \\
\text { by the students. }\end{array}$ \\
\hline $\begin{array}{l}\text { 4. Student dissatisfaction with } \\
\text { the assignment instructions, } \\
\text { referral and failure procedures, etc. }\end{array}$ & $\begin{array}{l}\text { To plan more integrated approach for } \\
\text { assignment instructions, clearer marking } \\
\text { criteria, and faster feedback; to have clearer } \\
\text { policies in place. }\end{array}$ & $\begin{array}{l}\text { Tutors are required to revise and cross- } \\
\text { check the assignment instructions and } \\
\text { marking criteria and make them accessible } \\
\text { on BREO for each module; faster return } \\
\text { of feedback to students. }\end{array}$ \\
\hline
\end{tabular}


Table 5

Comparison of equivalent aspects covered in the 1 st and 2 nd surveys.

\begin{tabular}{|c|c|c|c|c|c|c|c|c|c|c|c|c|c|}
\hline \multirow[t]{2}{*}{ Q } & \multirow[t]{2}{*}{ Survey items } & \multicolumn{6}{|c|}{ 1st survey results (\%) } & \multicolumn{6}{|c|}{ 2nd survey results (\%) } \\
\hline & & $\mathrm{E}$ & G & A & $P$ & $E \& G$ & $A \& P$ & $\mathrm{E}$ & G & A & $\mathrm{P}$ & $\mathrm{E} \& \mathrm{G}$ & $A \& P$ \\
\hline 1 & Registration process & 27 & 60 & 10 & 3 & 87 & 13 & 20 & 57 & 23 & 0 & 77 & 23 \\
\hline 3 & Teaching at local institution & 23 & 60 & 17 & 0 & 83 & 17 & 7 & 60 & 30 & 3 & 67 & 33 \\
\hline 4 & Course/unit handouts & 30 & 50 & 17 & 3 & 80 & 20 & 17 & 63 & 20 & 0 & 80 & 20 \\
\hline 5 & Local tutor support & 20 & 40 & 40 & 0 & 60 & 40 & 33 & 21 & 43 & 3 & 54 & 46 \\
\hline 9 & Textbook availability & 27 & 46 & 17 & 10 & 73 & 27 & 17 & 46 & 17 & 20 & 63 & 37 \\
\hline 10 & Usefulness of CD ROMS (1st survey); weekly materials online (2nd survey) & 23 & 37 & 27 & 13 & 60 & 40 & 23 & 54 & 10 & 13 & 77 & 23 \\
\hline 13 & UK tutor support & 20 & 47 & 30 & 3 & 67 & 33 & 53 & 10 & 37 & 0 & 63 & 37 \\
\hline 17 & Voice Café (1st survey); WIMBA live classroom (2nd survey) & 20 & 13 & 17 & 50 & 33 & 67 & 20 & 40 & 20 & 20 & 60 & 40 \\
\hline 19 & E-learning training and support; IT training materials online (2nd survey) & 17 & 27 & 43 & 13 & 44 & 56 & 13 & 54 & 30 & 3 & 67 & 33 \\
\hline 20 & Assignment instructions & 13 & 63 & 17 & 7 & 76 & 24 & 23 & 57 & 17 & 3 & 80 & 20 \\
\hline 21 & Assignment submission procedures & 20 & 53 & 14 & 13 & 73 & 27 & 30 & 50 & 3 & 17 & 80 & 20 \\
\hline 22 & Assignment feedback & 10 & 40 & 37 & 13 & 50 & 50 & 13 & 54 & 13 & 20 & 67 & 33 \\
\hline 23 & Referral procedure & 19 & 37 & 38 & 6 & 56 & 44 & 13 & 50 & 12 & 25 & 63 & 37 \\
\hline 24 & Failure procedures & 27 & 27 & 18 & 28 & 54 & 46 & 19 & 29 & 19 & 33 & 48 & 52 \\
\hline 29 & Overall experience of online support & 13 & 47 & 30 & 10 & 60 & 40 & 30 & 47 & 6 & 17 & 77 & 23 \\
\hline \multirow[t]{2}{*}{30} & Overall experience of undertaking the MBA & 27 & 40 & 30 & 3 & 67 & 33 & 30 & 47 & 20 & 3 & 77 & 23 \\
\hline & Average Percentage: & 21 & 43 & 24 & 11 & 65 & 35 & 23 & 47 & 19 & 11 & 70 & 30 \\
\hline
\end{tabular}

(Key: E = Excellent, $\mathrm{G}=$ Good, $\mathrm{A}=$ Average, $\mathrm{P}=$ Poor).

However, despite the effort made for improvement after the first survey some areas did worse, including the registration process (down from 87\% to 77\%; textbook availability (73\%-63\%); and the failure procedures (54\%-46\%). Both local and UK tutor support (questions 5 and 13) had become worse, down from 60\% to 54\%; and from 67\% to 63\%, respectively. Most surprisingly, teaching by local institutions (question 3) had fallen from $83 \%$ to $67 \%$. This was a startling drop when the team considered that the teaching had not changed a great deal. So perhaps this reflected that there had been a change in student expectations in the context of changes to other elements of the programme.

The changes that had been made to the programme following the first survey are discussed below in more detail, set against the findings from the two surveys, to indicate how the gains in student satisfaction were achieved.

\subsubsection{Introduction of WIMBA}

WIMBA was adopted in August 2008 to replace the Voice Café system (voice over the Internet). Voice Café had shown a lot of problems in the past (such as unclear sound, vague images, limited functions, poor user interface and being search-engine sensitive) and the university had many complaints from students using the system. WIMBA was judged a more advanced system with more effective audio and video components. It is a 'plug-in' system linked to Blackboard courses and units, enabling users to record voice announcements, audio blogs, video clips, send email messages and conduct live audio/video sessions. For each unit the UK unit leader was assigned additional online contact time including more 'WIMBA live classroom' sessions which were normally given some weeks before the submission deadline of each assignment. One student commenting on this after a WIMBA session said that 'it is the best teaching session after the induction'. The students also liked the idea of archiving the WIMBA sessions as an additional e-learning resource, as it allowed them, and those who have missed a class, to review the archived files. The Blackboard tracking statistics showed that for the seven WIMBA archives which were made available for one cohort of students during March 2009, there were 107 hits, which indicated that the students appreciated the effort the university had made to provide this facility. As reported above, most respondents considered WIMBA the better e-learning supporting system as the second survey showed that students' perception of WIMBA was significantly more positive than that for Voice Café (60\% vs. 33\%).

\subsubsection{Improved course delivery}

A significant change made in the blended learning support system was the restructuring of the format and timing of the online learning content. This was changed so that all content was presented online in a standard format and made available on a weekly basis, consistent with the learning schedule. This was a significant change compared to the previous system where the main course materials were provided on a CD for each unit. In comparing the two elements (provision of CD ROMs vs. material online weekly), the percentage of students viewing course provision as being 'excellent' plus 'good' increased from $60 \%$ to $77 \%$. The respondents also liked the audio and video clips prepared by the UK tutors on specific topics, and $77 \%$ wished to have more such clips for each of the units.

\subsubsection{Improved course and unit information}

In the first survey, students expressed their wish that each unit handbook provide all the information about the unit, in particular including details about the exams and assignments, and examples of good assignments. The format of all the unit 
handbooks were therefore expanded and standardised, and as a result the students reported that they were clearer about requirements for assignments in each unit that they took. In terms of response to the questionnaire, the percentage of positive responses for this area remained the same, at $80 \%$.

\subsubsection{Provision of online training materials}

Subsequent to the first survey, a range of training materials, including an ICT guide and audio/video clips for using the university's digital library were developed and made available online to the students. As a result, in the second survey the students rated the MBA ICT guide, the WIMBA live classroom guidelines, the clips on digital library, and the Harvard referencing guidelines, as the most useful tools, followed by the guide for using Net-mail (the e-mailing system for students). Overall, the survey evaluation of 'excellent' plus 'good' for the e-learning training and supporting materials available rose from $44 \%$ in the first survey to $67 \%$ in the second.

\subsubsection{Improved usability of the e-learning tool}

As mentioned above, in the first survey one respondent had commented that the university's customised Blackboard was 'the most under-used tool'. However, after the changes were introduced, statistical tracking showed very high hit rate for the weekly online material for all the units. For example, a total of 182 students from four randomly selected units in Oman (semester 2 of the academic year 2008/9) showed a total of over 8047 hits within one week. These included the weekly online course content (6566 hits), WIMBA live classroom (657 hits), and ICT training guide (824 hits). This meant an average of 44 hits per student per week, nearly five times of the number of hits before the change was made.

\subsubsection{Assessment related areas}

As mentioned earlier, the student perception of the assignment related topic areas had been generally improved, including assignment instructions, assignment submission procedures; assignment feedback, and referral procedure. In terms of providing students with feedback on their assignments, the first survey showed $50 \%$ of the respondents rated this either 'excellent' or 'good'. Subsequently, a great deal of effort was made to improve this area. There was improvement in this rating (to 67\%), but this was still a fairly low score for a topic on which a lot of effort had been made. Some students felt that for some assignments the feedback was too general and not enough to help them improve future assignments. However, many students also acknowledged that some lecturers gave very good feedback. Clearly, given the constraints on lecturers' time, fully satisfying student demands in this area will always be a challenge. However, regarding failure procedures, students felt less happy (48\% 'excellent' and 'good' combined) compared with the result in the first survey (54\%). This indicated that it might be more useful to provide more support to students at risk.

\subsubsection{Other topics}

Other findings from the survey included that respondents were not keen on writing wiki-text and blogs on Blackboard (and neither were the lecturers!). In addition, students really disliked receiving information on plagiarism and using the Turnitin system for submitting assignments (over $80 \%$ said 'no', only $9 \%$ said 'yes'). By contrast, they much liked the examples of good and bad assignments for each unit (80\% said 'very useful' or 'useful').

In terms of the students' overall experience of this e-learning MBA, while the first survey showed that $66 \%$ of students graded this as 'excellent' or 'good', in the second this increased to 70\% as a result of changes to the programme and its delivery (Fig. 3). Given the effort made, the course providers had hoped for better ratings, indicating that there was still more work to do.

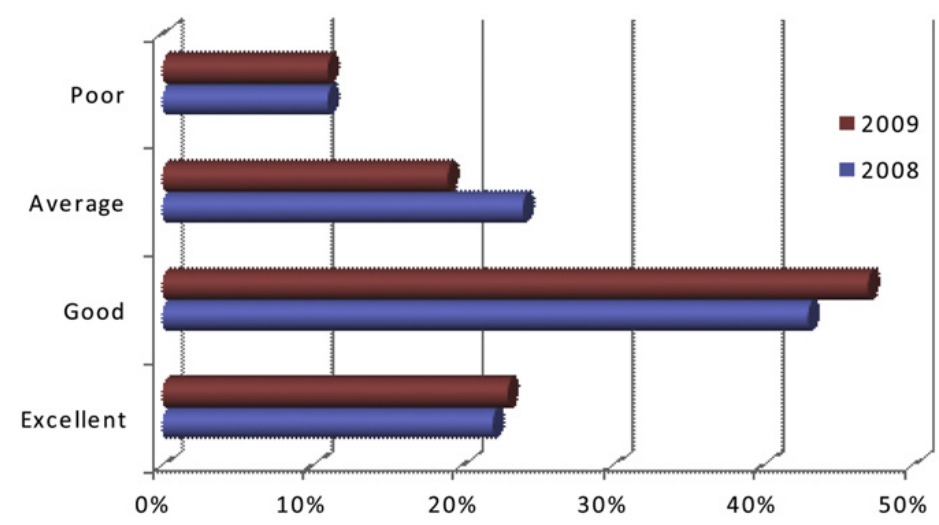

Fig. 3. Comparison of the overall results of the first and second surveys. 
Table 6

Comparison of equivalent questions from all three surveys (\% by category).

\begin{tabular}{|c|c|c|c|c|c|c|c|c|c|c|c|c|c|c|c|c|c|c|}
\hline \multirow[t]{2}{*}{ Q } & \multirow[t]{2}{*}{ Survey items } & \multicolumn{6}{|c|}{ 1st survey results (\%) } & \multicolumn{6}{|c|}{ 2nd survey results (\%) } & \multicolumn{5}{|c|}{ 3rd survey results (\%) } \\
\hline & & $\mathrm{E}$ & G & A & $P$ & $\mathrm{E} \& \mathrm{G}$ & $A \& P$ & $E$ & G & A & $P$ & $\mathrm{E} \& \mathrm{C}$ & $\mathrm{A} \& \mathrm{P}$ & $\mathrm{E}$ & G & A & $\mathrm{E} \& \mathrm{G}$ & $A \& P$ \\
\hline 1 & Registration process & 27 & 60 & 10 & & 87 & 13 & 20 & 57 & 23 & & 77 & 23 & 29 & 943 & 22 & 672 & 28 \\
\hline 3 & Teaching at local institution & 23 & 60 & 17 & & 83 & 17 & & 760 & 30 & & 67 & 33 & & 34 & 43 & 849 & 51 \\
\hline 4 & Course/unit handouts & 30 & 50 & 17 & & 80 & 20 & 17 & 763 & 20 & & 80 & 20 & & 53 & 18 & 2061 & 38 \\
\hline 5 & Local tutor support & 20 & 40 & 40 & & 60 & 40 & 33 & 21 & 43 & & 54 & 46 & 24 & 453 & 12 & 1077 & 22 \\
\hline 10 & Usefulness of CD ROMS (1st survey); weekly materials online (2nd survey) & 23 & 372 & 27 & 13 & 60 & 40 & 23 & 54 & 10 & 13 & 77 & 23 & 29 & 49 & 18 & 478 & 22 \\
\hline 13 & UK tutor support & 20 & 47 & 30 & & 67 & 33 & 53 & 310 & 37 & & 63 & 37 & 22 & 49 & 29 & 071 & 29 \\
\hline 19 & $\begin{array}{l}\text { E-learning training and support; IT training materials online (2nd \& 3rd } \\
\text { surveys) }\end{array}$ & 17 & 27 & 43 & 13 & 44 & 56 & 13 & 54 & 30 & & 67 & 33 & 12 & 49 & 37 & 261 & 39 \\
\hline 21 & Assignment submission procedures & 20 & 53 & 14 & 13 & 73 & 27 & 30 & 50 & & 17 & 80 & 20 & 18 & 376 & 6 & 094 & 62 \\
\hline 29 & Overall experience of online support & 13 & 473 & 30 & 10 & 60 & 40 & 30 & 47 & 6 & 17 & 77 & 23 & 22 & 255 & 16 & 677 & 22 \\
\hline 30 & Overall experience of undertaking the MBA & 27 & 40 & 30 & & 67 & 33 & 30 & 47 & 20 & & 77 & 23 & 57 & 724 & 18 & 081 & 18 \\
\hline & Average Percentage: & 22 & 48 & 25 & & 69 & 31 & 26 & 48 & 21 & & 74 & 26 & 24 & 449 & 22 & 573 & 27 \\
\hline
\end{tabular}

(Key: $\mathrm{E}=$ Excellent, $\mathrm{G}=$ Good, $\mathrm{A}=$ Average, $\mathrm{P}=$ Poor).

\subsection{Outcome of the third survey}

The third survey was conducted in 2010 with 49 valid responses obtained of which 40 conducted in class and 9 online. Table 6 shows the results from the 11 questions which covered the same areas as in the first and second surveys.

The MBA programme had been further changed following the second survey, but not radically in most areas. So for many of the questions that were the same it is not surprising that the results were fairly similar. However, on the key question that asked about the students' overall experience of taking the MBA course (No. 30), there was a encouraging trend in improvement on the percentage of 'excellent, rising from $27 \%$ in the first survey round, to $30 \%$ in the second and $57 \%$ in the third. Some other findings, however, were disappointing. For example, evaluation of the 'teaching at the local partner universities' was again rated lower than previously, which clearly showed that the UK university needed to take action to improve the situation. This fall in rating was partly counterbalanced, however, by a large jump in the rating of quality of local tutor support, reflecting the very significant effort that had been put into improving this area. Fig. 4 compares the results of all three surveys, averaged over the 11 questions in common.

As mentioned earlier, the questionnaires were 'semi-structured' in the sense that respondents could add comments to clarify or expand their questionnaire answers. Indeed, respondents were specifically encouraged to make comments (whether positive or negative) where they felt this could improve future course provision. All replies were useful, though not surprisingly some respondents asked for additional resources (e.g. more tutor time or faster response on assignment feedback) that were unlikely to be met without a fundamental change in level of staff provision.

A further issue raised related to the perennial question of the proportion of group work to Individual work. One respondent put this concern eloquently:

The grave challenge I faced is the group assignments. Success of team work depends on choosing right members for the team. Everybody just formed teams in the first business school weekend where we didn't have any idea about each other. The collectivist mentality of the local culture played a negative role in working with assignments. Free-riders carried on with ease at the expense of my own time and sweat.

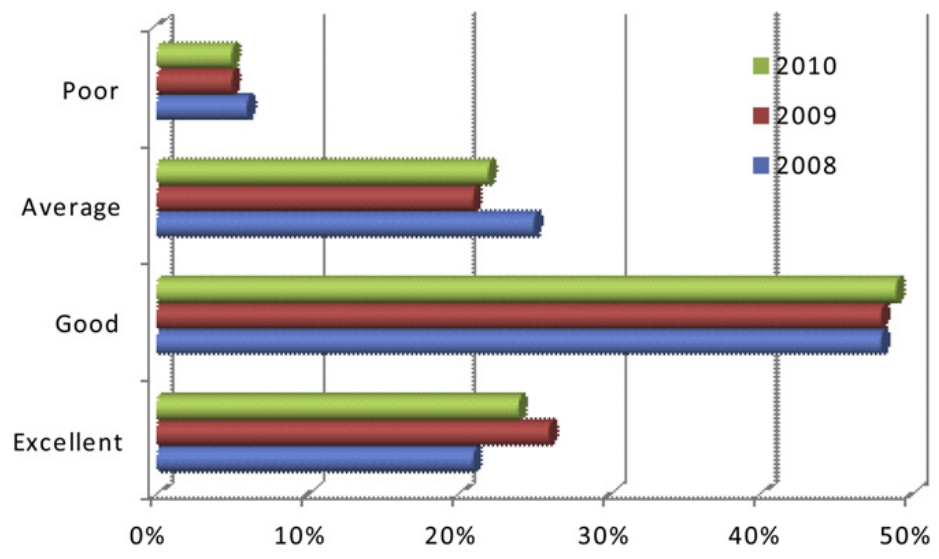

Fig. 4. Comparing the results of all three survey rounds. 
Overall, the surveys gave a generally positive picture of how the students felt about the course, with some highly complementary remarks being made when students were asked to summarise their level of satisfaction with the course.

\section{Research limitations}

Like all research, this research faced some limitations. These included:

- Change in the survey question sets over time. This is not thought to be a major impediment to the overall value of the surveys, as most of such changes were determined by straightforward factors, such as questions being no longer relevant (the situation having changed), or where new questions were designed to measure course changes following a previous survey round.

- Response rate: The overall response rate, though good, was low enough that significant 'response bias' could have occurred, for example, disgruntled students not participating in the surveys or vice versa. However, the surveys were deliberately made voluntary to avoid the alternative problems of forcing ill-considered responses, or implicit pressure for good responses.

Overall, common-sense considerations (including directness of the questions, number of students surveyed, and nonmandatory nature of the surveys) suggested that the results are likely to be robust.

\section{Reflections and future recommendations}

Following the third survey round, the course team has stepped back to appraise the results as a whole, and consider the future of both the research and the programme. The overall appraisal is that significant improvements were made initially which impacted positively on student perceptions of the programme. Results have now largely plateaued, both for the overall perception of the programme, and in relation to many of the individual elements. For the most part, student perceptions have reached a reasonable level, but there are some elements where the perceptions remain relatively negative, including the provision of feedback on assignments, supporting students (and tutors) with the use of wikis, blogs, etc., and the perception of teaching by local tutors. (Note that the research method was not designed to illuminate this last issue which is clearly significant. It could, for example, be as simple as an inverse correlation with the improvement in the perceptions of the online materials provided: as students find those better, they want different things from the local tutors which the UK staff are not helping them provide. Or it could draw in quite complex differences in culture, in student expectations of a 'UK University experience' and, again, the ability of the UK staff to support local tutors in delivering that.)

In appraising the position, the authors recommend consideration of a two-track approach towards enhancing the programme's quality and effectiveness:

(1) Making incremental improvements arising directly from the third survey round;

(2) Incorporating insights from this research into a more fundamental change to the delivery of the programme.

Suggestions for incremental changes are:

- Firstly, the UK university provides new guidance and support to UK staff to help maintain a more consistent level of contact between UK staff and students across the different units.

- Secondly, contact between the UK lecturers and the local tutors at the partner institutions should be improved, again with guidance to all UK tutors on what they need to provide.

- Thirdly, assessment requirements should be made clearer. There are two options for addressing this. One is to brief the local tutors more thoroughly. The other is to ensure a greater flow of information from the UK staff which meets all the student needs. The second option seems the better one mainly because it eliminates the possibility of conflicting instructions between the UK and local tutors. UK tutors mark the assignment, so should be the source of all instructions on what to do. Information can be provided in the assignment brief, in a podcast and by provision of detailed assessment criteria. In addition a discussion board can be provided prior to submission of assignments where all queries will be addressed so that it is accessible to all students. University-wide new standards on communicating assessment requirements would support the MBA team in relation to this issue, for example with guidance on assessment criteria.

- Fourthly, full sample exam papers and marking guidelines should be provided. This has been the case on many units, but not uniformly.

- Finally, ensure more consistent use of the Blackboard technology by UK staff so that all assignments are set up on TurnItIn and are all marked online. At the moment, this is still difficult for assignments requiring blind double marking online, but it is anticipated that the technology can be fixed soon to serve this purpose. The consistent approach should help reduce the turnaround times on marking and therefore improve the timeliness of feedback. 
The authors recognise that this is a difficult territory. As they are now, policies do not sufficiently help people understand how to deliver online. They don't adequately help staff find time for this work when a physical classroom of students may seem a more immediate (or appealing) priority. It takes time to help staff deliver blended learning effectively and to feel at ease with new techniques.

The second track under consideration, therefore, takes a more radical approach. It looks at a step-change in the quality and interactivity of the online materials. This is expected to have a number of benefits. It reduces reliance on the local tutors, and changes their role more towards supporting students, an area where the student perceptions have increased very positively over the period of the research. It will increase contact with the UK tutors, reinforcing this positively viewed element of the programme. It improves the consistency in the use of online interactivity across units and thereby of the student experience because more online materials are provided 'ready-made' for any tutor (UK and local) to use. It also means that their use of wikis, blogs and other interactive tools is planned and structured for them. For these to be effective the authors recognise that there are still training and support needs for staff in using such materials.

Alongside the University's formal mechanisms for gathering and responding to student feedback, this research has given valuable and very specific insights into the areas to work on to improve the student experience. As noted by Singh (2003) learning technologies and delivery media continue to evolve and progress rapidly and therefore it is of paramount importance that blended learning programmes incorporate an evaluation dimension with the capacity to evaluate the quality and effectiveness of the learning programme and performance of the learners in a continuous way.

\section{Conclusions}

The paper discusses the evaluation of a blended learning MBA programme provided by a UK university at one of its main overseas partner-institution sites - Oman. The study used action research, and the evaluation involved a sequence of semistructured questionnaire surveys of students' perceptions of the course.

Findings from these surveys, plus other internal review procedures, were used to make changes in both course content and course delivery approaches. The research contrasts with research into the evaluation of e-learning courses which relies on data gathered just once, and where cross-sectional designs have been applied. By contrast the 'longitudinal' approach (Dillon, Madden, \& Firtle, 1994) employed here has enabled the charting of changes over time, thus enriching the process of course design, and monitoring the changing satisfaction of students and other stakeholders.

The findings give credence to the view that an e-delivery approach is well suited to work-based part-time MBA students who are 'relatively mature, already business-aware, conversant with information technology, and have access to the elearning facilities and resources required' (Priestman, 2010). Furthermore, the findings support the claim of Gurău and Drillon (2009) that student feedback can provide valuable data to evaluate and improve the functioning and performance of an elearning system. Rajasingham (2009) concluded that educational paradigms that challenge conventional teaching methods are becoming increasingly possible with the help of the increasing sophistication in information technology. The authors of the current research recognise that student satisfaction reported for this course emanate in no small measure from design and implementation approaches made possible by this improvement in information technology. Moreover, by identifying areas for course improvement, this research has attempted to implement the concept of 'evaluation as an instrument of quality enhancement, rather than just quality assurance', as suggested by Deepwell (2007).

Finally, while Martinez-Arguelles et al.'s (2010) 'quality dimensions have been used effectively in this study seen from the framework of Moore's (2006) 'Pillars of quality', we note that a further evaluation can incorporate many more dimensions. Future research can be directed towards incorporating these various dimensions for a more complete approach to evaluation.

\section{Acknowledgements}

The authors wish to thank the respondents and the MBA team of the UK University for their support in this study.

\section{References}

Al-Gattoufi, S., Al-Naabi, S., \& Gattoufi, B. (2007). Readiness for shifting from traditional higher education learning system to an E-learning system: a case study from the Sultanate of Oman. Journal of College Teaching and Learning, 4(11), 55-60.

Baskerville, R. (1999). Investigating information systems with action research. Communications of AIS, 2(19).

Buzzetto-More, N. (2008). Student perceptions of various e-learning components. Interdisciplinary Journal of Knowledge and Learning Objects, 4, 113-135. Deepwell, F. (2007). Embedding quality in e-learning implementation through evaluation. Journal of Educational Technology and Society, 10(2), 34-43.

Dillon, W. R., Madden, T. J., \& Firtle, N. H. (1994). Marketing research in a marketing management (3rd ed.). Burr Ridge: Richard Irwin Inc.

Elango, R., Gudep, V. K., \& Selvam, M. (2008). Quality of e-Learning: an analysis based on e-learners' perception of e-learning. The Electronic Journal of e-Learning, 6(1), 31-44.

Goold, A., Craig, A., \& Coldwell, J. (2007). Accommodating culture and cultural diversity in online teaching. Australasian Journal of Educational Technology, 23(4), 490-507.

Guri-Rosenblit, S. (2009). Distance education in the digital age: common misconceptions and challenging tasks. Journal of Distance Education, 23(2), 105-112. Jara, M., \& Mellar, H. (2010). Quality enhancement for e-learning courses: the role of student feedback. Computers and Education, 54(3), 709-714.

Kidney, G., Cummings, L., \& Boehm, A. (2007). Toward a quality assurance approach to e-learning courses. International Journal on E-Learning, 6(1), 17-30.

Lam, P., \& Bordia, S. (2008). Factors affecting student choice of e-learning over traditional learning: student and teacher perspectives. International Journal of Learning, 14(12), 131-139.

Landry, B. J., Payne, D., \& Koger, M. S. (2008). From 'chalk and talk' to online offerings: keeping pace with technology in education. International Journal of Management Education, 2(3), 300-317. 
Lapointe, L., \& Reisetter, M. (2008). Belonging online: students' perceptions of the value and efficacy of an online learning community. International Journal on E-Learning, 7(4), 641-665.

Martínez-Argüelles, M., Castán, J., \& Juan, A. (2010). How do students measure service quality in e-learning? A case study regarding an internet-based university. Electronic Journal of e-Learning, 8(2), 151-159.

Moore, J. C. (2006). The sloan consortium quality framework and the five pillars. The Sloan Consortium (SLOAN-C). (a Consortium of Institutions and Organisations Committed to Quality Online Education).

Musawi, A. A. (2002). Issues and prospects of E-Learning in Oman. In P. Barker, \& S. Rebelsky (Eds.), Proceedings of world conference on educational multimedia, hypermedia and telecommunications 2002 (pp. 17-18). Chesapeake, VA: AACE.

Pillay, H., \& Kimber, M. (2009). Quality assurance in higher education: for whom and of what? International Journal of Management Education, 3(3/4), 270281.

Priestman, T. (2010). MBA approval document. University of Bedfordshire. 26 May 2010.

Rajasingham, L. (2009). Breaking boundaries: quality e-learning for global knowledge society. International Journal of Emerging Technologies in Learning, 4(1), $58-65$.

Saunders, M. (2003). Maximising learning in evaluation of e-learning environments. Evaluating e-Learning, (Galecia Project, Portugal).

Singh, H. (2003). Building effective blended learning programs. Education Technology, 43(6), 51-64.

Singh, G. (2011). The adoption and diffusion of elearning: a comparative case study using Giddens' theory of structuration. Doctoral thesis, University of Huddersfield.

UNESCO (1998). World declaration on higher education for the twenty-first century: vision and action. Proceedings of the World Conference on Higher Education, Paris, 5-9 October, 1998.

Williams, M., \& Williams, J. (2010). Evaluating a model of business school students' acceptance of web-based course management systems. The International Journal of Management Education, 8(3), 59-70.

Zygouris-Coe, V., Swan, B., \& Ireland, J. (2009). Online learning and quality assurance. International Journal on E-Learning, 8(1), $127-146$.

Dr. Bentley is Senior Lecturer at the University of Bedfordshire UK. She teaches undergraduate Business and Management, MBA Operations Management, MSc Logistics Management, and Operations for Logistics and Supply Chain Management. Her current research interests include e-learning approaches, research-led curriculum design, and logistics strategies. She has published papers in all these areas. She is Fellow of the Higher Education Academy and Chartered member of the Chartered Institute of Logistics and Transportation.

Dr. Selassie is Senior Lecturer at the University of Bedfordshire UK. Besides lecturing he undertakes various research and scholarly activities. His research interests include internationalisation of SMEs, the impact of culture on business, and international business education. He is a Fellow of the Higher Education Academy and member of the Academy of International Business. He serves on the Editorial Boards of international journals that publish research results in areas of international business and marketing.

Elizabeth Parkin is Senior Lecturer in Strategy and Academic Director for the MBA programmes at the University of Bedfordshire, UK. Her research interests are in teaching and learning, in particular focussing on the integration of skills and different functional areas in business courses. She is a Bedfordshire Teaching Fellow in recognition of the work she did in developing the integrated first year programme, the "Pod", which has been the subject of a number of conference presentations. She is a Fellow of the Higher Education Academy and a member of the Chartered Institute of Marketing. 